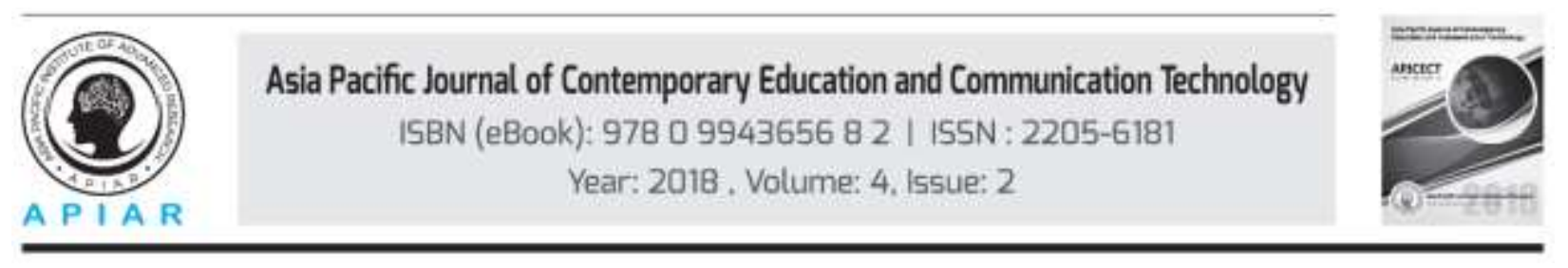

\title{
THE HUMAN INTERACTION PERSPECTIVE OF PROJECT MANAGEMENT SOFTWARE ADOPTION
}

\author{
Ahmed Alojairia, Abdullah Basiouni ${ }^{b}$ \\ aKing Fahd University of Petroleum and Minerals (KFUPM), Dhahran, Saudi Arabia \\ bYanbu University College, Yanbu Industrial City, Saudi Arabia \\ Corresponding Email: basiounia@rcyci.edu.sa
}

\begin{abstract}
This study examines the user's interaction of new-implemented Project Management Software (PMS) in a Middle Eastern Telecommunication Company (METC) using a qualitative research method. One-third of the collected sample described the implemented PMS as compatible with the business environment, and $25 \%$ found it capable of scheduling and allocating resources. However, about half of the users commented on the PMS as unreliable and ineffective. To overcome PMS unreliability and ineffectiveness, $41 \%$ of the users found ways to work around the challenges to get the job done. Therefore, system developers and providers are advised to investigate these challenging issues and to engage users in the development and implementation stages actively.
\end{abstract}

Keywords: Project Management Software, Echo Method, Human Interaction, Technology Adoption.

\section{Introduction}

Information Technology (IT) plays an important role in the project management field to assist project management teams with the necessary solutions in minimizing effort and time required to manage different project's activities. Due to the increasing demand for project management software, many software packages have been developed with a wide range of capacities and prices (El-Zamzamy \& Hegazy, 1998; Anbari et al., 2008).

With the project management software, it is possible for project managers to effectively and efficiently analyze the immense amount of data that is required to monitor and control the progress of many interrelated tasks. Generally, literature lacks in the field of project management software and individuals that shed light on system effectiveness that fit between software and its users (e.g., Nafkha \& Wiliński, 2016; Simmonds \& Pence, 2017). Thus, this study qualitatively assesses the interaction between PMS and its users through multiple openended questions in a Middle Eastern Telecommunication Company (METC) to uncover the challenging situations that its users experienced.

\section{Literature Review}

PMS is widely used to manage project tasks, people, and financial resources. While PMS supports both the basic function of project management such as project scheduling and resources allocation, researchers emphasized the importance of incorporating additional nontraditional tasks such as collaboration, information sharing, and knowledge management (Chen et al., 2006; Cline et al., 2010; Reyck, 2010). 
Furthermore, the complexity of a project came from the interaction between human and technical resources of the project. Thus, PMS carries features for project integration, coordination, communication, and control (Cline et al., 2010). The complexity of the project increases when a project is covering different geographical areas that raise the necessity for adding more features like allowing process management, collaborative communication, and support (Chen et al., 2006).

A study by Pollack-Johnson and Liberatore (1998) described that among the 688 members of the Project Management Institute, 240 respondents of all project management professionals emphasized the use of PMS to some extent. Furthermore, 95\% of those users are using the tool for planning, while $80 \%$ use it for control. While $95 \%$ of the individuals in this study indicated that the primary use of the software is as a planning tool, these results are not congruent with the outcome of other studies. The other studies indicated that information systems for project planning are mainly used for communication and representation rather than for optimization and the limited knowledge about the systems between the software user and use as a planning tool in general (Herrolen, 2005; Kumar et al., 2017).

The collaborative PMS can be divided into four main components from management support, knowledge management, process management, and communication and collaboration support. In such collaborative systems, users can search for information, generate reports, assess project performance, and identify deviations (Chen et al., 2006). However, web-based collaboration PMS is recently trending, especially for expensive and long-term projects (Fernandez-Aleman, et al., 2016; Lusa \& de Miranda, 2017).

The knowledge management perspective of the Case-Based Project Management Assistant (CaBMA) can be used as an example of an added feature to the traditional PMS. CaBMA can help capture different plans and deal with them as cases, enhancing them in each project cycle and reusing the cases to generate plans when they deviate from existing knowledge (MunozAvila \& Xu, 2008; Vijayasarathy et al. 2016). According to Liberatore et al. (2003) and Anbari et al. (2008), there is a significant relationship between PMS users' satisfaction, decision styles, and PMS usage. Thus, this suggests that the level of PMS utilization increased as the users were aware and able to use PMS. However, Anbari et al. (2008) cautioned researchers and PMS users not to rely exclusively on PMS generated reports, but also to further analyze those reports by taking into consideration other business and environmental factors. Consequently, the decision to acquire a PMS may be affected by users (i.e., the human factor) level of satisfaction and utilization for the proposed PMS package, rather than the software technical capability and generated report (Nitithamyong \& Skibniewski, 2011).

\section{Research Methodology}

This study was conducted at METC which is located in the Middle East. The METC employs professionals from different disciplines such as information technology, marketing, and engineering. It has an impressive business performance evidenced by its customers who are not limited to SABIC, Royal Commission for Jubail and Yanbu, and Saudi Aramco, but also cover other SME companies.

The data was collected using the Echo method originally developed by Bavelas (1942). According to Poile (2008), the Echo method is a powerful qualitative research tool that reflects back the opinion of the sampled population and determines the different characteristics of interaction between parties within the studied sample and. Consequently, many researchers (Cunningham, 2001; Poile, 2008; Fernández-Alemán et al., 2016) commented that the Echo method can effectively help researchers undercover hidden problems given in a real-life scenario. They appreciated the methodology strength derived from the development that Echo method went through during the last few decades until it became known for understanding numerous social 
and organizational interests. Cunningham (2001) and Fernández-Alemán, et al. (2016) emphasized the importance of conducting qualitative research that catches the sensitivity and complex interactions between people and technology, which cannot be examined by traditional quantitative research. The qualitative methodology has an analytical part in which the interviews transcribed and then further classified by grouping and ordering the data and transcripts to important information.

This study examined a total of 28 one-on-one interviews from the METC in different managerial levels as follows:

Table 1: Managerial ranking $(\mathrm{N}=28)$ of the participants

\begin{tabular}{lllll}
\hline & Number of Participants & \multicolumn{2}{l}{ Managerial Ranks } \\
\cline { 3 - 5 } & & Directors & Managers & Supervisors \\
& 3 & 15 & 10 \\
\hline \multirow{2}{*}{ Total } & $28(100 \%)$ & $3(10.7 \%)$ & $15(53.6 \%)$ & $10(35.7 \%)$ \\
\hline
\end{tabular}

During each interview, the participant was asked to give concrete examples of helpful and nonhelpful interactions with other parties involved when using the company's PMS. The interview concluded with a description of the common way of doing business transactions, especially when non-helpful situations arise. Additionally, this process of interviewing a participant following specific procedure protocols resulted in people retelling about recent interactions that impacted them. This shows the robust capability of the Echo method when explaining a phenomena using the "subjective probability" approach.

\section{Results and Analysis}

The interviews were transcribed and categorized based on the Echo method. They were placed into three categories: namely helpful, not so helpful, and variety handling mechanisms. Table 2 lists the resulted categories and a classical example of each category.

Table 2: Classical examples of the resulted categories

\begin{tabular}{lcl}
\hline Category & \# of Examples & Classical Example \\
\hline Helpful & 201 & $\begin{array}{l}\text { Shows actual work versus planned work and } \\
\text { how many resources in each activity. }\end{array}$ \\
Not So Helpful & 134 & $\begin{array}{l}\text { Requires some software knowledge in } \\
\text { addition to PMS knowledge to work } \\
\text { effectively. }\end{array}$ \\
$\begin{array}{l}\text { Variety Handling } \\
\text { Mechanisms }\end{array}$ & 131 & $\begin{array}{l}\text { Most reports that need functions are not } \\
\text { available in PMS and are conducted using } \\
\text { Excel. }\end{array}$ \\
\hline Total & 466 & \\
\hline
\end{tabular}

Under each category, there are similar examples that were grouped to create subgroup items. This process helped capture emerging items. Seven items emerged under the first category, (i.e., helpful), see Table 3. Control is the most helpful item (30.3\%), followed by scheduling and resource allocation (24.9\%) While decision-making received the smallest number of examples 
(5\%), followed by Communication and Collaboration with $9 \%$ of the examples. Tables 4 and 5 show the distribution of items that are not helpful and in the various handling mechanisms categories.

Table 3: Percentage of helpful examples (201 examples)

\begin{tabular}{ll}
\hline Helpful Items & $\%$ \\
\hline Control & $30.3 \%$ \\
Scheduling \& Resource Allocation & $24.9 \%$ \\
Reliability & $2.0 \%$ \\
Ease of Use & $14.9 \%$ \\
Decision Making & $5.0 \%$ \\
Flexibility & $13.9 \%$ \\
Collaboration \& Communication & $9.0 \%$ \\
\hline Total & $100 \%$ \\
\hline \multicolumn{1}{c}{ Table 4: Percentage of not-so-helpful examples (134 examples) } \\
\hline Not-So-Helpful Items & $\%$ \\
\hline Lack of Control & $3.7 \%$ \\
Poor Scheduling \& Resource & $7.5 \%$ \\
Allocation & $43.3 \%$ \\
Unreliability & $25.4 \%$ \\
Lack of Ease of Use & $5.2 \%$ \\
Poor Decision Making & $14.9 \%$ \\
Inflexibility & $100 \%$ \\
\hline Total &
\end{tabular}

Table 5: Percentage of variety handling mechanism examples (131 examples)

\begin{tabular}{ll}
\hline Variety of Handling Items & $\%$ \\
\hline Accepting & $14.5 \%$ \\
Manipulating & $19 \%$ \\
Using Other Tools & $41 \%$ \\
Seeking Help & $21.5 \%$ \\
Rechecking and Redoing & $4 \%$ \\
\hline Total & $100 \%$ \\
\hline
\end{tabular}

Quantitatively, we calculated the Interaction Effectiveness (IE) average ratio of the total number of helpful examples (201 examples) over the total number of not so helpful examples (134 examples) to help to understand the relative interaction effectiveness between the two categories. The IE ration is 1.5 which demonstrate that the helpful examples overcome the not so helpful examples. However, this conclusion depends on other company IE ratios and the industry average IE ratio. 


\section{Discussion}

The reported results illustrate that (30.3\%) of the METC users perceived that PMS is helpful as a control tool, while (43.3\%) users claimed that the PMS is not a reliable tool. To overcome the unreliability and other not so helpful issues, (41\%) of users tried to find other ways to work around the PMS system to get the information required to produce the requested report.

The control item, which received the highest number of examples in the helpful category, cannot be considered a positive outcome, rather only a significant item within this category. Many projects are unique and consequently, may not fit with a rigid standardized system. Standardization and heavy use of control may hinder the innovative spirit of a unique project and may push users to generate reports to satisfy their supervisors, instead of projects that are actually necessary to produce. Therefore, PMS should be used to justify invested money and to facilitate project management in the organizations, from a control perspective.

When PMS is used for scheduling and resource allocation, the users need to assure that their efforts are observed throughout the project life cycle. Furthermore, most PMS users utilize the tools for scheduling and resource allocation in the early stage of the project only, unlike controlling, which is used through the whole lifecycle of the project. Thus, what is perceived could be different from what was scheduled and allocated earlier, and will contentiously update for the scheduling and resource allocating that is necessary for the complete life of projects.

Additionally, in the helpful category, we found that reliability is a helpful capability that was mentioned in only $2 \%$ of the examples. We should not be surprised by this number because PMS users consider reliability as a default and basic advantage for using PMS in the first place. It is the fulfillment of transportation by using cars, a benefit that is seldom praised by drivers when they discuss cars, for example. Further, users also mention other car features like engine power, economical fuel consumption, and cheap spare parts.

However, the unreliability item as a not so helpful issue was mentioned in (43.3\%) of the examples. While the basic assumption of PMS is reliability, Woodwoorth (1989), Reyck (2010), and El-Zamzamy \& Hegazi (1998) reported numerous reliability issues of PMS when it comes to optimizing the utilization of limited resources or when dealing with unique projects. Surprisingly, similar challenges were introduced by some of the users; to quote: "You need to check your output against older forecast". The reliability of PMS is an issue that could affect the level of use of existing for PMS users. Furthermore, this similar with the Technical Readiness (TR) theory emphasizing individual online behavior that is influenced by how users perceive the quality of the system's generated reports and figures (Parasuraman, 2000; Rojas-Méndez et al, 2017).

In the variety-handling category, a majority of the users (41\%) used other tools to overcome the PMS challenges, which needs further investigation. Many of the collected examples indicated that Excel was used to generate alternative reports or figures when the PMS produced incorrect results. Moreover, the selection of the PMS is an issue for organizations; it seems that organizations are not following proper selection criteria to ensure there is optimal benefit to the organization. Thus, there is a lack of employees' involvement in the PMS selection decision to determine what they require for the system to function.

Rechecking and redoing was the least observed, making up only $3 \%$ of the examples. An explanation is that the nature of this action, which not aligned with a use of sophisticated systems. In other words, the user may ask himself, "If I need to do frequent manual checks or redo the task using an alternative tool, then from the beginning, why I should use a PMS?" 


\section{Conclusion \& Recommendations}

This study qualitatively examined the interaction between project management software, PMS and its users in a Middle Eastern Telecommunication Company (METC) using the Echo method. Additionally, the Interaction Effectiveness (IE) ratio of helpful examples and not so helpful examples was 1.5. The majority of the helpful examples by the PMS users fall under "Control" (30\%). Furthermore, the problems associated with excessive control in organizations were discussed above. However, the majority of the not so helpful examples fall under "Unreliability" (43\%). Further, a large proportion of the various handling examples fall under "Using Other Tools" (41\%) and we found that Excel is the preferred "used other tool" method to perform functions.

PMS technology providers need to look at the results of this and similar studies carefully to improve their software packages. For example, this study revealed that PMS users are extensively using Excel to resolve many shortcomings of the existing PMS. The lack of functionality or low processing of the sought functions needs to be addressed. Furthermore, there are other issues such as the perception that PMS is unreliable. PMS developers need to sponsor focused studies to address the sub-categories of reliability issues in order to tackle them effectively.

This research has several limitations that need to be considered in the future. For example, detailed insights and comparisons between users years of managerial experience and the number of years of experience in the PMS filed. Additionally, studying the nature of task activity (fieldwork vs. office work) of the employee, regardless of his/her position, could be another area of future interest. Extensive and repeated qualitative research conducted to calculate the Interaction Effectiveness (IE) ratio for different companies in numerous industries, systems, and organization attributes, the result will be useful in IE ratios comparisons. It can be used for benchmarking, which will help assess different companies based on their IE ratio. Therefore, with this data proposals can be submitted for further improvement. Thus, a comprehensive psychometric tool can be developed and sent to a larger sample of companies across different industrial sectors to prove the reported research results statistically.

\section{Acknowledgement}

The authors of the paper would like to acknowledge the support brought by King Fahd University of Petroleum \& Minerals (KFUPM), Dhahran, Saudi Arabia and Yanbu University College, Royal Commission for Yanbu Project, Saudi Arabia. 


\section{References}

i. Anbari, F., Bani A. A., \& Mony, W., 2008. Impact of Organizational and Project Factors on Acceptance and Usage of Project Management Software and Perceived Project Success.Project Management Journal, 39(2), pp. 5-33.

ii. Bavelas, A., 1942. A method for Investigating Individual and Group Ideology.Sociometry Volume 5, pp. 371-377

iii. Chen, F., Nunamaker, J., \& Romano, N., 2006. A collaborative project management approach and framework for its supporting systems.Journal of International Technology and Information Management, 15(2), pp. 1-15.

iv. Cline, M., Guynes, C., \& Simard, K., 2010. Ace project as a project management tool. American Journal of Business Education, 3(6), pp. 63-68.

v. Cunningham, J., 2001. Researching Organizational Values and Beliefs: The Echo Approach. 1st ed. Westport: Greenwood publishing group.

vi. El-Zamzamy, H.,\&Hegazy, T., 1998. Project management software that meets the challenge.Journal of Cost Engineering, 40(5), pp. 25-33.

vii. $\quad$ Fernández-Alemán, J., Carrillo-de-Gea, J., Meca, J., Ros, J., Toval, A., \& Idri, A., 2016. Effects of Using Requirements Catalogs on Effectiveness and Productivity of Requirements Specification in a Software Project Management Course.IEEE Transactions on Education, 59(2), pp. 105-118.

viii. Herroelen, W., 2005. Project Scheduling-Theory and practice.Production and Operation Management Society, 14(4), pp. 413-432.

ix. Kumar, V., Wilfred, A., \& Seridevi, H., 2017. Comparative Study of Time-Cost Optimization.International Journal of Civil Engineering and Technology (IJCIET). 8(4), pp. 659-663.

x. Liberatore, M. \& Pollack-Johnson, B. 2003. Factors influencing the usage and selection of project management software.IEEE Transactions on Engineering Management, 50(2), pp. 164-172.

xi. $\quad$ Lusa A. \& de Miranda, L. 2017. An Introduction to the Resource Constrained Project Scheduling Problem Solving Techniques, Optimization and Decision Support Systems for Supply Chains. Switzerland: Springer.

xii. Munoz-Avila, H. \& Xu, K., 2008. CaBMA: a case-based reasoning system for capturing, refining and reusing project plans.Knowledge Information Systems, 15(2), pp. 215-232.

xiii. Nafkha, R. \& Wiliński, A. 2016. The Critical Path Method in Estimating Project Duration.Information Systems in Management. 5(1), pp. 78-87.

xiv. Nitithamyong, P. \& Skibniewski, M., 2011. Success factors for the implementation of web-based construction project management systems.Construction Innovation Journal, 11(1), pp. 14-42.

xv. Parasuraman, A., 2000. Technology Readiness Index (Tri): A Multiple-Item Scale to Measure Readiness to Embrace New Technologies.Journal of Service Research, 2(4), pp. 307 - 320.

xvi. Poile, C., n.d. The Echo method: investigating Socio-technical interactions, Proceedings of the 2008 ICSE Workshop on Socio-Technical Congruence. Leipzig, Germany: s.n.

xvii. Pollack-Johnson, B., \& Liberatore, M., 1998. Project management software usage patterns and suggested research directions for future developments.Project Management Journal, 29(2), pp. 19-28.

xviii. Reyck, B., 2010. Effective project planning: making the most of project planning tools. Production and Inventory Management Journal,46(2), pp. 10-25. 
xix. Rojas-Méndez, J., Parasuraman, A., \& Papadopoulos, N., 2017. Demographics, attitudes, and technology readiness: A cross-cultural analysis and model validation.Marketing Intelligence \& Planning, 35(1), pp. 18-39.

xx. Simmonds, D. \& Pence, N., 2017.The Impact of Task-Methodology Fit on CPM/PERT Diagramming Performance: An Experimental Investigation. Springfield, Illinois: Proceedings of the Twelfth (2017)Midwest Association for Information Systems Conference, May 18-19, 2017.

xxi. Vijayasarathy, L. \& Butler, C., 2016. Choice of Software Development Methodologies: Do Organizational, Project, and Team Characteristics Matter?IEEE Software, 33(5), pp. 86-94.

xxii. Woodworth, B., 1989.Is resource-constrained project management software reliable?Cost Engineering Journal, 31(7), pp. 7-11. 